\title{
Taking Personality to the Next Level: What Does It Mean to Know a Person?
}

\author{
SIMINE VAZIRE and ROBERT WILSON
}

\begin{abstract}
What does it mean to know a person? In his famous article, McAdams (1995) addresses this question from the perspective of personality psychology and concludes that personality traits are "the psychology of the stranger." To really know someone, you need to know more than just how they typically think, feel, and behave on average (a common definition of traits). You need to know how their thoughts, feelings, and behaviors change depending on their role and context, why those fluctuations occur (the underlying motives and causes of those patterns), and how they make sense of their own patterns over time (their life narrative). In this essay, we argue that although there has been little empirical work on within-person fluctuations in personality, the time is ripe to examine these patterns. New technology has made it possible to quantify momentary thoughts, feelings, and behaviors, and to track the contextual factors that underlie these fluctuations (i.e., "personality signatures"). By capturing individual differences at this dynamic level, we can gain a better understanding of how people differ from one another. This will also open the door to new research questions, such as investigating the amount of insight people have into their own and others' personality signatures.
\end{abstract}

"We are sometimes as different from ourselves as we are from others."

Francois de La Rochefoucauld

\section{INTRODUCTION}

\section{Personality Traits and Personality States}

When we describe what people are like, we often begin by talking about their general tendencies. For example, we might describe Sally as an agreeable person and Tricia as a disagreeable person. These trait descriptions allow us to easily describe Sally and Tricia's past behavior and anticipate their future behavior. Furthermore, we can use these broad individual differences to predict a wide range of outcomes such as occupational success and divorce

Emerging Trends in the Social and Behavioral Sciences. Edited by Robert Scott and Stephan Kosslyn. (C) 2015 John Wiley \& Sons, Inc. ISBN 978-1-118-90077-2. 
(Barrick \& Mount, 1991; Karney \& Bradbury, 1995; Ozer \& Benet-Martinez, 2006).

However, people vary quite a bit around these average tendencies. Sally may be agreeable most of the time, but surely she has moments when she interrupts others or acts unkind. Although these fluctuations are usually treated as noise in personality trait research, they are themselves an individual difference. Indeed, we can think of Sally's fluctuations on agreeableness as a part of her personality. Perhaps Sally is typically agreeable but fluctuates a lot, whereas Tricia is consistently disagreeable. Focusing on the within-person fluctuations in personality states does not contradict the fact that there are also stable individual differences at the trait level.

Fleeson $(2001,2004,2007)$ has proposed a very elegant way of conceptualizing personality traits and states in a single model (Figure 1). According to Fleeson's density distribution approach to personality, personality traits (e.g., Sally and Tricia's average levels of agreeableness) are summaries of each person's more nuanced density distribution of states. That is, Sally's trait level of agreeableness (high) is the mean of her state agreeableness. But the full distribution of Sally's states gives us a much richer picture of Sally's personality - we can see that her personality states range all the way from low agreeableness to high agreeableness (although the latter state is much more common than the former for Sally). In contrast, Tricia's trait level of agreeableness (low) is basically all we need to know to discern what she is like on agreeableness-she does not fluctuate much around her typical, pretty disagreeable state.

Fleeson's empirical work shows that most people exhibit almost all levels of a given trait at some point during a typical week. Most of us have

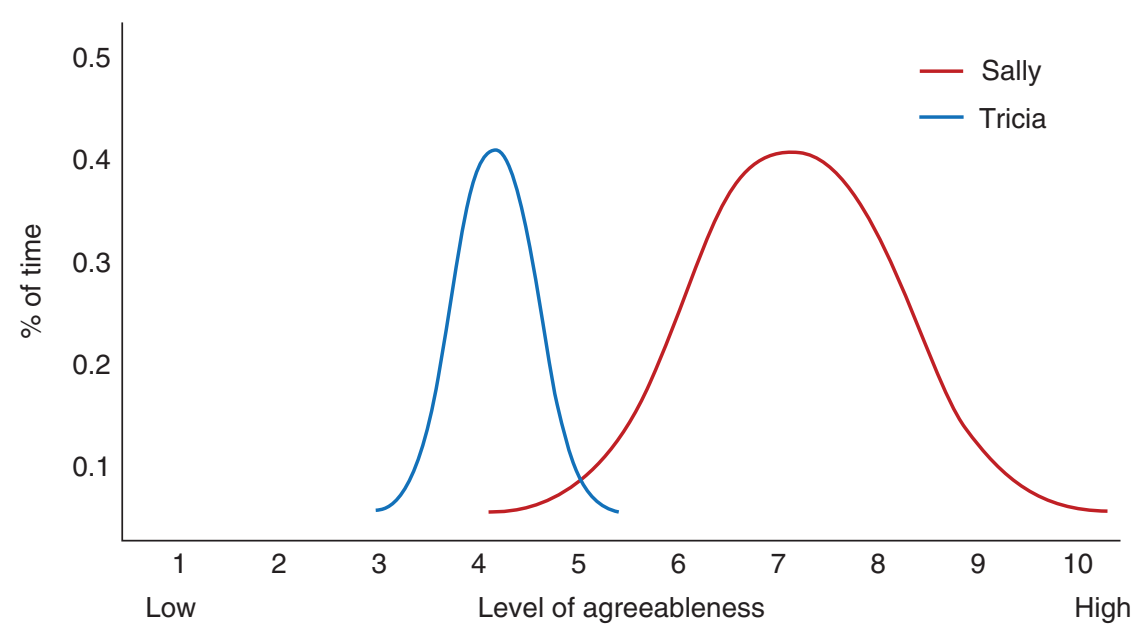

Figure 1 Personality as a density distribution of states. 
some agreeable moments and some disagreeable moments. However, there are very robust individual differences in our average states-some of us consistently experience agreeable states much more often than disagreeable states, and others show the opposite pattern. Moreover, these individual differences in average states are stable from week to week-someone who experiences mostly agreeable states 1 week is likely to do so the next week. The same goes for other traits (e.g., extraversion, neuroticism, etc.).

By conceptualizing personality traits as density distributions of states, we can get closer to McAdams's ideal of knowing not just what a person is like on average but also understanding the dynamic ways in which they fluctuate over time and across situations. Knowing the shape of a person's distribution of personality states provides more nuance than just knowing their trait level, and provides the opportunity for even further understanding. Specifically, once we know how much people fluctuate around their global traits, we can investigate the causes of those fluctuations.

\section{FOUNDATIONAL RESEARCH}

\section{Personality Signatures}

The brute fact that Sally is sometimes very agreeable and at other (rare) times quite disagreeable is valuable information about Sally's personality in itself. However, it raises other questions. For example, what causes Sally to vary on agreeableness? Can we predict these fluctuations based on Sally's role, her mood, or her environment? These are the kinds of questions that motivated Mischel and Shoda to develop the Cognitive Affective Personality System (CAPS) model of personality (Mischel \& Shoda, 1995). In CAPS, Sally's unique pattern of cause and effect is her "if ... then" contingency, or her personality signature.

This model takes us another level deeper in our understanding of personality. The goal is not just to describe how much people's personality states fluctuate, but to explain those fluctuations. Some of the fluctuations may be caused by similar triggers for most people. For example, most people are probably more agreeable when they are with people they like compared to when they are with people they do not like. To the extent that a person's "if ... then" contingencies are driven by universal triggers, that does not really give us much information about how people differ from one another. However, some personality triggers are probably idiosyncratic. Perhaps Sally is more agreeable around people she knows well, whereas Tricia is more agreeable (to the extent that she is ever agreeable) around strangers. These unique "if ... then" contingencies are what constitute a person's unique personality signature. 
According to the CAPS model, the influence of external triggers on personality states is mediated by cognitive and affective processes. That is, Sally's cognitive and affective reaction to strangers (vs close others) is what explains her drop in agreeableness. Thus, the entire dynamic system, from external triggers to mental processes to behavior, is what constitutes a person's personality. As such, to fully understand a person, you need to understand not just their global traits and their density distribution of states but also the triggers that predict their fluctuations and the cognitive and affective processes that explain these patterns. This idea is not unique to CAPS. In addition to McAdams, many other personality theorists have argued that understanding people's idiosyncratic reactions to different situations is fundamental to capturing their personality (Allport, 1937; Lewin, 1936; Magnusson \& Endler, 1977).

\section{EMPIRICAL RESEARCH}

So far, most of the work on personality signatures has been theoretical (Allport, 1937; McAdams, 1995; Mischel, 1973, 2004; Mischel \& Shoda, 1995, $1998,1999)$. There is very little empirical work examining personality beyond global traits (cf., Fournier, Moskowitz, \& Zuroff, 2008; Shoda, Mischel, \& Wright, 1994). Fleeson has pushed the field into new territory by documenting that most people vary quite a bit around their average states (i.e., traits), and that this within-person variation is itself a fundamental aspect of a person's personality. However, the research has pretty much stopped there. The next frontier for personality research is to empirically examine the patterns that may be hidden within these density distributions-personality signatures. Here, we review some of the fundamental questions that need to be addressed.

What Are the "Active Ingredients" of Situations That Trigger Fluctuations in Personality States? We know how to measure the "then" part of the "if ... then" contingency-the personality states (although we rely on the assumption that the taxonomy of personality traits also applies to states, an assumption that needs further examination; see Borkenau \& Ostendorf, 1998). However, there is very little consensus about the taxonomy of the "if" part of the contingency-the situational triggers. What are the important dimensions along which situations differ? Several researchers have suggested taxonomies or catalogues of situational variables that are meant to capture the "psychologically active ingredients" of situations-the factors that affect how people think, feel, and behave (e.g., Funder, Furr, \& Colvin, 2000; Moos, 1973; Saucier, Bel-Bahar, \& Fernandez, 2007). This is a good start, but more exploratory research needs to be done, including research combining the 
"if" and "then" halves of the personality signature, to identify which aspects of situations can predict the variance in people's personality states. This is the first step in measuring personality signatures.

Do Most People Have Idiosyncratic Personality Signatures? Once we identify situational triggers that explain fluctuations in state personality, we can examine the extent to which these triggers are idiosyncratic or universal. Are Sally's fluctuations in agreeableness caused by the same triggers as Tricia's and everyone else's? Fleeson's results cannot directly speak to this-even though most people vary quite a bit around their average states, it is still possible that the same triggers account for the variance in each person's states. Many personality theorists firmly believe that this is not the case - that Sally's fluctuations are caused by different triggers (and different cognitive and affective reactions to triggers) than are Tricia's fluctuations. This intuition is central to all idiographic approaches to personality, including McAdams'. It is almost an article of faith in personality theory that you cannot fully know a person without understanding her unique personality signatures Thus, the next step for personality research in this area is to empirically measure the idiosyncrasies of personality signatures.

What Processes Mediate the Effect of Triggers on Personality States? Once we can identify people's unique personality signatures, the next step in understanding the person is delineating the cognitive and affective processes that explain how the situational triggers produce variations in thoughts, feelings, and behaviors. This step involves going from simply describing people's patterns (e.g., Sally is less agreeable around strangers than around friends) to explaining them (e.g., Sally feels anxious around strangers, which causes her to act disagreeable). One empirical example of this type of research is Downey's work on rejection sensitivity (Downey \& Feldman, 1996; Downey, Freitas, Michaelis, \& Khouri, 1998; Downey, Mougios, Ayduk, London, \& Shoda, 2004). These studies indicate that people high in rejection sensitivity are more likely to interpret ambiguous information (e.g., a partner leaving the experiment) as rejection and this cognitive interpretation leads to the self-fulfilling prophecy, where rejection sensitivity ultimately leads to unsatisfying romantic relationships and dissolution (Downey \& Feldman, 1996; Downey et al., 1998). This is an example of moderated mediation, where the trigger (i.e., ambiguous partner behavior) causes people high in rejection sensitivity (i.e., moderator) to engage in the self-fulfilling prophecy (i.e., moderated mediator), which leads to negative relationship outcomes. More research is needed to identify other such dynamic within-person processes that account for individual differences in personality signatures. Ultimately, 
this research would help us not only to predict when people will fluctuate from their global traits but also to understand why they do so.

\section{CUTTING-EDGE RESEARCH}

Methodological Advances

One of the main reasons that little empirical research has been conducted on personality signatures is that there are important methodological obstacles to such research. Idiographic approaches to personality require extensive repeated measurements in order to obtain enough power to investigate within-person processes. Furthermore, to study personality signatures, it is necessary to measure both situational variables (i.e., potential triggers) and personality states over time. In addition, people may not be consciously aware of their triggers, their personality states, or both, and thus ideally these would be measured both subjectively and objectively. Finally, these variables should be measured in people's natural environments in order to have the best chance of capturing ecologically valid assessments of people's patterns of thinking, feeling, and behaving in response to the triggers they encounter in their daily lives. Fortunately, new technological developments make it easier and cheaper than ever to collect such data. Here, we describe several methods that can be used to achieve these goals, and we give an example of one of our ongoing studies that implements these methods (Vazire et al., 2014).

Daily Life Studies: Ecological Momentary Assessment (EMA). Daily life studies have been around for over 100 years and come under a variety of names such as diary methods, experience sampling methods (ESMs), ambulatory assessment, and ecological momentary assessment (EMA). The common theme is that these methods are conducted outside of the laboratory in approximately real time, focus on systematically measuring the behavior, perceptions, environment, and/or physiology of participants, and are assessed on repeated occasions (Mehl \& Conner, 2012). These methods provide remarkably rich information about people but historically they have been very difficult to implement (for a review, see Wilhelm, Perrez, \& Pawlik, 2012). Fortunately, the proliferation of smartphones and expansion of Internet access has made the collection of daily life data much easier (see discussion in Miller, 2012). For example, it is now feasible for researchers to conduct an EMA study by writing a web questionnaire that can be accessed from any smartphone or Internet-connected device. In a modern EMA design, participants can be prompted by text or e-mail to log into a web questionnaire and complete a report about their thoughts, feelings, behavior, and / or situation. It is possible to prompt participants several times per day for several days or weeks and 
ask them to give "status updates" of both situational variables (e.g., Did you like the people you were with? Was it a familiar situation?) and personality states (e.g., Did you act extraverted? Did you feel calm?).

In our ongoing study, over 400 college student participants have completed EMA reports up to four times per day for 2 weeks. Our questionnaire asks participants to report on their mood (11 items, e.g., "happy," "lonely"), personality states (10 items, e.g., "rude," "reliable") and situation (13 items, e.g., "how much did you like the people you were with?," "how deep/substantive was the conversation?"). We enter participants into a lottery for each survey they complete (which costs us about 22 cents per completed survey). Our average response rate has been $52 \%$, with $75 \%$ of participants completing at least 15 of 56 surveys $(M=29.4, S D=15.2)$.

Daily Life Studies: Electronically Activated Recorder (EAR). EMA provides valuable information about subjective experiences but this method is hampered by the limitations inherent in any self-report measure, such as blind spots in self-knowledge and consistency motivations (Paulhus \& Vazire, 2007; Vazire, 2010). There is also a concern that self-reports of certain constructs (e.g., depth of conversation) are so subjective that between-person comparisons cannot be trusted without some form of external corroboration. Fortunately, technological advances are making it possible to passively collect a rich trove of information about situations and behaviors that can act as a validation check for EMA and potentially add complimentary information about if-then triggers not captured by self-reports.

For example, our ongoing study incorporates the electronically activated recorder (EAR), which is an iPhone- or iPod-based application designed to record brief sound snippets from participants' natural environment as they go about their day. We ask our participants to clip an iPod Touch with the EAR software to the outside of their clothing during the first week of the EMA portion of the study. The EAR is programmed to record 30-s audio files every $9.5 \mathrm{~min}$, giving us over 700 audio files per participant. One benefit of the EAR recordings is that they can be coded and recoded as many times as desired. There is no established taxonomy of situations and the ability to capture behavior broadly is highly desirable because the same audio files can be used to test a range of behaviors depending on the hypothesis of interest. Our team of research assistants is currently coding sound files on items that parallel the EMA variables (e.g., personality states, depth of conversation) as well as other variables that are unique to the EAR data (e.g., coding specific behaviors such as laughing, apologizing, bragging). Taken together, the EAR codings and EMA ratings gives us a multimethod repeated measures design that is ideal for assessing common if-then personality triggers and distinctive personality signatures. 


\section{FUTURE DIRECTIONS}

What are the most important questions that remain to be answered? One aim of our current study is to examine the average within-person relationships among the situation variables and the personality states. That is, on average, what do personality signatures look like for each situation-personality state combination? For example, on average, are people happier when they are having deeper conversations? The next aim is to examine individual differences around this average within-person slope. That is, are there idiosyncratic variations in these personality signatures? For example, is happiness more contingent on depth of conversation for some people than others? From there, we can examine moderators (e.g., which people show a stronger relationship between depth of conversation and happiness?) and mediators (e.g., is the association between depth of conversation and happiness accounted for by self-disclosure?). This allows us to predict who will have what personality signatures (moderators) and understand what internal processes might explain these patterns (mediators).

We hope this project will lay the groundwork for assessing people's personality signatures, and that these methods can then be used to study new basic and applied research questions. Here, we give a few examples of research questions that we will be able to tackle once these methods have been validated.

\section{Self- and Other-Knowledge of Personality Signatures}

A fundamental question that cuts across all subdisciplines of psychology is how well do people know themselves (Vazire \& Carlson, 2011; Vazire \& Wilson, 2012; Wilson, 2009). In the realm of personality, we now have quite strong evidence that people have some insight into their global traits, but also have important blind spots in this arena (Carlson, Vazire, \& Oltmanns, 2013; Vazire, 2010). However, very little is known about how much self-knowledge people have about the dynamic aspects of their personality. Do people know how much their personality states fluctuate? Do they know the causes of those fluctuations? That is, do they know their personality signatures? McAdams argues that to really know another person, we must understand them at this dynamic level. The same can be said of self-knowledge: for a person to really know herself would mean for her to know not only how she is on average but also when and why she deviates from her typical personality profile.

One intriguing possibility is that self- and other-knowledge of personality signatures may be asymmetrical. The research on self- and other-knowledge of global personality traits suggests that there are some traits the self can judge more accurately than can close others, and some traits that close others 
can see accurately but the self cannot. The same might be true of personality signatures. For example, people might have good self-insight into what triggers their fluctuations in neuroticism, but close others may be better at identifying the factors that trigger fluctuations in agreeableness (because agreeableness is more observable to others and perhaps less salient to the self). Identifying the bright spots and blind spots in self- and other-knowledge of personality signatures can help us understand the process of self-perception and the function that self-insight and self-deception might be serving in people's everyday lives.

Moreover, once we know what aspects of their personality signatures people tend to be unaware of, we can develop interventions to try to improve self-knowledge in these areas. For example, if people tend to be unaware of their idiosyncratic triggers for agreeableness, giving them feedback may help them select the situations that bring out their desired levels of agreeableness. To the extent that we can identify the mediators that explain why these triggers cause fluctuations in personality states, we may even be able to intervene in that process and help people break maladaptive patterns.

\section{How Does Personaltty Influence the Selection of Situations?}

So far we have discussed environmental triggers as if they are independent drivers of personality fluctuations, but people actively navigate their world and personality likely plays an important role in the selection of environments. Such an indirect effect of personality may help explain individual differences in the presence or absence of certain triggers in daily life. For example, an extrovert may attend more parties, and being at parties is likely a situational trigger to act more extroverted. Untangling this reciprocal relationship presents exciting new opportunities for understanding dynamic person-by-situation interactions.

\section{How Can Research about Personality Signatures be Applied to Real-World}

PROBLEMS?

Another exciting avenue for research on personality signatures is the potential application of this work in real-world contexts. For example, many mental disorders are characterized by unique patterns of fluctuations in moods or personality states (e.g., bipolar disorder). Developing better techniques for assessing these patterns will help us understand these disorders better, and may also help with treatment. For example, the methods described could be used to identify people's idiosyncratic triggers for manic or depressive episodes, and people could be given empirical feedback about their own unique triggers. The same could be done for other health and mental health 
problems (e.g., chronic pain, insomnia, social anxiety). This feedback could then be used to help people select healthier situations or break unhealthy patterns of "if ... then" contingencies.

Similarly, research on personality signatures has the potential to be very useful in organizational settings. One challenge in organizations is identifying people who will thrive in various kinds of positions (e.g., leadership positions, high stress positions, etc.). For example, research suggests that there are important individual differences in how people respond to high status positions and winning verses losing (Mehta, Jones, \& Josephs, 2008). Specifically, people with high testosterone levels who lose in a competition are less likely to want to compete a second time but more likely to want to compete if they win. On the other hand, winners and losers with low testosterone do not differ in their willingness to compete a second time. This is an excellent example of how understanding people's personality signatures can help predict context-specific behavior. Ultimately, this kind of research could help people make better choices for themselves and their organizations, and maximize person-environment (or person-role) fit.

\section{CONCLUSION}

What makes a person unique is not just their global patterns of thinking, feeling, and behavior but also the pattern of responses to external triggers in theireveryday life. To know a person well requires moving beyond understanding the general tendencies and learning what "pushes their buttons." New tools provide a way to quantify fluctuations in thoughts, feelings, and behavior with unprecedented detail and precision. Social scientists now have the opportunity to study life as it is actually lived at the individual level in order to better understand how people differ from one another. Examining personality at this dynamic level will help move our field forward to a more fine-grained and comprehensive understanding of personality. It is an exciting time to be a social-personality psychologist.

\section{REFERENCES}

Allport, G. W. (1937). Personality: A psychological interpretation. New York, NY: Holt. Barrick, M. R., \& Mount, M. K. (1991). The big five personality dimensions and job performance: A meta-analysis. Personnel Psychology, 44(1), 1-26.

Borkenau, P., \& Ostendorf, F. (1998). The big five as states: How useful is the five-factor model to describe intraindividual variations over time? Journal of Research in Personality, 32(2), 202-221.

Downey, G., \& Feldman, S. I. (1996). Implications of rejection sensitivity for intimate relationships. Journal of Personality and Social Psychology, 70(6), 1327-1343. 
Downey, G., Freitas, A. L., Michaelis, B., \& Khouri, H. (1998). The self-fulfilling prophecy in close relationships: Rejection sensitivity and rejection by romantic partners. Journal of Personality and Social Psychology, 75(2), 545-560.

Downey, G., Mougios, V., Ayduk, O., London, B. E., \& Shoda, Y. (2004). Rejection sensitivity and the defensive motivational system: Insights from the startle response to rejection cues. Psychological Science, 15(10), 668-673.

Fleeson, W. (2001). Toward a structure-and process-integrated view of personality: Traits as density distributions of states. Journal of Personality and Social Psychology, 80(6), 1011-1027.

Fleeson, W. (2004). Moving personality beyond the person-situation debate the challenge and the opportunity of within-person variability. Current Directions in Psychological Science, 13(2), 83-87.

Fleeson, W. (2007). Situation-based contingencies underlying trait-content manifestation in behavior. Journal of Personality, 75(4), 825-862.

Fournier, M. A., Moskowitz, D. S., \& Zuroff, D. C. (2008). Integrating dispositions, signatures, and the interpersonal domain. Journal of Personality and Social Psychology, 94(3), 531-545.

Funder, D. C., Furr, R. M., \& Colvin, C. R. (2000). The riverside behavioral Q-sort: A tool for the description of social behavior. Journal of Personality, 68(3), 451-489.

Karney, B. R., \& Bradbury, T. N. (1995). The longitudinal course of marital quality and stability: A review of theory, methods, and research. Psychological Bulletin, 118(1), 3-34.

Lewin, K. (1936). Principles of topological psychology. New York, NY: McGraw-Hill.

Magnusson, D., \& Endler, N. S. (Eds.) (1977). Personality at the crossroads: Current issues in interactional psychology. Hillsdale, NJ: Erlbaum.

McAdams, D. P. (1995). What do we know when we know a person? Journal of Personality, 63(3), 365-396.

Mehl, M. R., \& Conner, T. S. (Eds.) (2012). Handbook of research methods for studying daily life. New York, NY: Guilford Press.

Mehta, P. H., Jones, A. C., \& Josephs, R. A. (2008). The social endocrinology of dominance: basal testosterone predicts cortisol changes and behavior following victory and defeat. Journal of Personality and Social Psychology, 94(6), 1078-1093.

Miller, G. (2012). The smartphone psychology manifesto. Perspectives on Psychological Science, 7(3), 221-237.

Mischel, W. (1973). Toward a cognitive social learning reconceptualization of personality. Psychological Review, 80(4), 252-283.

Mischel, W. (2004). Toward an integrative science of the person. Annual Review of Psychology, 55, 1-22.

Mischel, W., \& Shoda, Y. (1995). A cognitive-affective system theory of personality: Reconceptualizing situations, dispositions, dynamics, and invariance in personality structure. Psychological Review, 102(2), 246-268.

Mischel, W., \& Shoda, Y. (1998). Reconciling processing dynamics and personality dispositions. Annual Review of Psychology, 49(1), 229-258. 
Mischel, W., \& Shoda, Y. (1999). Integrating dispositions and processing dynamics within a unified theory of personality: The cognitive-affective personality system. In Handbook of personality: Theory and research (Vol. 2, pp. 197-218). New York, NY: Guilford Press.

Moos, R. H. (1973). Conceptualizations of human environments. American Psychologist, 28(8), 652-665.

Ozer, D. J., \& Benet-Martinez, V. (2006). Personality and the prediction of consequential outcomes. Annual Review of Psychology, 57, 401-421.

Paulhus, D. L., \& Vazire, S. (2007). The self-report method. In R. W. Robins, R. C. Fraley \& R. Krueger (Eds.), Handbook of research methods in personality psychology (pp. 224-239). New York, NY: Guilford Press.

Saucier, G., Bel-Bahar, T., \& Fernandez, C. (2007). What modifies the expression of personality tendencies? Defining basic domains of situation variables. Journal of Personality, 75(3), 479-504.

Shoda, Y., Mischel, W., \& Wright, J. C. (1994). Intraindividual stability in the organization and patterning of behavior: Incorporating psychological situations into the idiographic analysis of personality. Journal of Personality and Social Psychology, 67(4), 674-687.

Vazire, S. (2010). Who knows what about a person? The self-other knowledge asymmetry (SOKA) model. Journal of Personality and Social Psychology, 98(2), 281-300.

Vazire, S., \& Carlson, E. N. (2011). Others sometimes know us better than we know ourselves. Current Directions in Psychological Science, 20(2), 104-108.

Vazire, S., \& Wilson, T. D. (Eds.) (2012). Handbook of self-knowledge. New York, NY: Guilford Press.

Wilson, T. D. (2009). Know thyself. Perspectives on Psychological Science, 4, 384-389.

Carlson, E. N., Vazire, S., \& Oltmanns, T. F. (2013). Self-Other knowledge asymmetries in personality pathology. Journal of Personality, 81(2), 155-170.

Vazire, S., Wilson, R. E., Solomon, B., Bollich, K., Harris, K., Weston, S., ... , Jackson, J. J. (2014). Personality and interpersonal roles. Study in progress.

Wilhelm, P., Perrez, M., \& Pawlik, K. (2012). Conducting research in daily life: A historical review. In M. R. Mehl \& T. S. Conner (Eds.), Handbook of research methods for studying daily life (pp. 62-86). New York, NY: Guilford.

\section{SIMINE VAZIRE SHORT BIOGRAPHY}

Simine Vazire is associate professor of psychology at the University of California, Davis. She is the director of the Personality and Self-Knowledge laboratory. Her research examines how well people know their own personality. She studies questions such as: Why do close others sometimes know us better than we know ourselves? What are the consequences of lacking self-knowledge? How can self-knowledge be improved? How are personality and social relationships related to well-being? Her research is funded by the National Science Foundation. 


\section{ROBERT WILSON SHORT BIOGRAPHY}

Robert Wilson is a graduate student in Psychology at the University of California, Davis. His research examines patterns in how people fluctuate around their average individual differences. The ways in which we vary in our daily lives can be a result of idiosyncratic responses to situations and other external forces. He uses a multimethod approach (self-reports, informant-reports, experience sampling, EAR audio recordings, Facebook behavioral codings) to examine how our personalities vary across environmental and social situations. He also examines the amount of self-awareness people generally have about their personality and behavioral patterns.

\section{RELATED ESSAYS}

Intersectionality and the Development of Self and Identity (Psychology), Margarita Azmitia and Virginia Thomas

Identity Fusion (Psychology), Michael D. Burhmester and William B. Swann Jr.

Resilience (Psychology), Erica D. Diminich and George A. Bonanno

Empathy Gaps between Helpers and Help-Seekers: Implications for Cooperation (Psychology), Vanessa K. Bohns and Francis J. Flynn

Grandmothers and the Evolution of Human Sociality (Anthropology), Kristen Hawkes and James Coxworth

Normal Negative Emotions and Mental Disorders (Sociology), Allan V. Horwitz

The Development of Social Trust (Psychology), Vikram K. Jaswal and Marissa B. Drell

Cultural Neuroscience: Connecting Culture, Brain, and Genes (Psychology), Shinobu Kitayama and Sarah Huff

Evolutionary Perspectives on Animal and Human Personality (Anthropology), Joseph H. Manson and Lynn A. Fairbanks

Born This Way: Thinking Sociologically about Essentialism (Sociology), Kristen Schilt

Clarifying the Nature and Structure of Personality Disorder (Psychology), Takakuni Suzuki and Douglas B. Samuel

Social Neuroendocrine Approaches to Relationships (Anthropology), Sari M. van Anders and Peter B. Gray

Theory of Mind (Psychology), Henry Wellman 